Virtual Mentor. July 2003, Volume 5, Number 7.

doi: 10.1001/virtualmentor.2003.5.7.jdsc1-0307

Journal Discussion

\title{
Financial Conflicts of Interest in Biomedical Research
}

\section{Researchers at academic research institutions may have to reject certain otherwise acceptable relationships with industry for the sake of preserving the public trust and avoiding even the perception of conflicts of interest.}

Jeremy Spevick

In the words of Dennis Thompson, a conflict of interest is "a set of conditions in which professional judgment concerning a primary interest (such as a patient's welfare or the validity of research) tends to be unduly influenced by a secondary interest (such as financial gain)" [1]. In the field of medical research a variety of activities can present conflicts of interest, from enrolling patients in clinical trials to industry-sponsored academic research. The latter case brings up questions about the integrity the research: Will industry sponsors begin to set research agendas? Will financial ties to the industry cause researchers to be less objective? Reports that industry-sponsored research is more likely to favor the drug of interest than research not funded by drug companies [2,3] has confirmed that the concerns are valid.

As of 2001, the majority of the $\$ 60$ billion the industry invested in research and development (R\&D) in basic biomedical discovery went to research projects at universities [4]. Researchers who accept funding from private industry must exercise scrupulous judgment in balancing their primary and secondary interests. Poorly managed conflicts of interest can, in the worst case, divert research agendas to issues of financial promise to industry and influence how researchers report their results. Poor judgment in managing conflicts of interest erodes the public's trust in universities to perform objective research and openly disseminate all results [5]. To maintain integrity in this era of increased university-industry relations, institutions have responded by developing various policies for faculty disclosure of potential conflicts of interest in their research and funding.

\section{How real are the perceived risks?}

In a November 2000 issue of JAMA, Elizabeth A. Boyd and Lisa A. Bero presented the results of a systematic review of how the University of California, San Francisco deals with faculty-industry relationships [6]. The study examined faculty disclosure forms from 1980-1999 maintained by the Office of Research Administration at the UCSF and provides insight into the variety of faculty-industry relationships. The authors assessed the extent to which faculty researchers had personal financial relationships with sponsors of their research, and how the university attempted to manage these potential conflicts of interest.

The study looked at all positive financial disclosures from clinical, basic, and social science faculty who were principal investigators. When the study concluded in 1999, 7.6 percent of UCSF's 888 faculty investigators who received external funding reported personal financial ties with sponsors of their research. (In 1985, this figure had been 2.6 percent.) Of the 488 total disclosures identified over the study period (some faculty members made multiple disclosures), 34 percent disclosed relationships that involved paid speaking engagements, 33 percent disclosed involvement in consulting agreements with sponsors, 32 percent involved an investigator holding a position on a scientific advisory board or board of directors. Additionally, 14 percent of faculty owned equity in the companies sponsoring their research [6]. 
At many research institutions, including UCSF, positive disclosures are presented to an advisory panel. At UCSF, the Chancellor's Advisory Panel on Relations with Industry meets monthly to review potential conflicts of interest and make recommendations to the university chancellor. Faculty must first comply with both state and federal guidelines. The federal guidelines, established in 1995, require investigators to disclose all "significant" financial interests that would "reasonably" appear to be related to sponsored research [7]. "Significant" is defined as $\$ 10,000$ per year income or 5 percent equity in a company. If a faculty member makes a disclosure under federal or state laws, the university will often ask for more detailed information, such as whether patent rights are involved or how graduate students will be involved.

When examining conflicts of interest, several factors help determine the potential severity of the conflict. The length of the investigator's involvement with the sponsor and the nature of the sponsoring agency can influence the advisory board's recommendations. Boyd and Bero note that, while conflict of interest policies establish the thresholds for which a disclosure must be made, they do not provide specific guidelines for managing conflicts [6]. At UCSF, the Advisory Board usually attempts to manage conflicts by requiring public disclosure of financial relationships and, in some cases, asking investigators to resign from positions at a sponsoring company.

Conflicts of interest are not new in academic research but are a concern that has moved to the forefront of academic research in the past 10 years. Since the end of World War II, a type of social contract has offered public support for basic research with the expectation that scientists will produce and disseminate knowledge to help society [8]. In the 1980s, the government sought to promote growth in the technology sector by increasing contact between researchers and industry. The Bayh-Dole Act of 1980 was the impetus for this change, giving universities the right to work with private industry to patent inventions that had been discovered or developed with federal funds. The potential value of biomedical discoveries has only recently reached a level that poses significant conflict of interest problems [4].

Once a potential conflict of interest is identified, it is still very difficult to determine if, and how, the conflict actually affects research agendas and outcomes. However, what is just as significant, is the public's perception of academic scientists. For hundreds of years, science has worked to develop an image of objectivity, where the pursuit of the truth is all that matters [8]. The public's fear is that increasing financial rewards may compromise how a researcher decides what to study or how data is interpreted and presented.

In a 1990 council report on medical center-industry relationships, the AMA addressed the possible consequence of this fear, warning that, "the mere perception of conflict of interest may be enough to cast significant doubt on an exemplary research program" [9]. It is not enough, then, for academic research institutions to monitor conflicts of interest and insure that they do not influence research agendas or reporting of results. They may have to reject certain otherwise acceptable relationships with industry for the sake of preserving the public trust.

\section{Questions for Discussion}

1. To what degree do you think that university-industry relations harm the objectivity of research?

2. Do you agree with the argument that the perception of conflicts of interest can erode the public's trust in academic research?

3. Are current laws and university policies effective at managing financial conflicts of interest?

4. In any research experience that you have had, were you aware of the source of your lab's funding? If so, did this ever impact your research?

\section{References}

1. Thompson DF. Understanding financial conflicts of interest. $N$ Engl J Med. 1993;329:573. View Article PubMed Google Scholar

2. Cho MK, Bero LA. The quality of drug studies published in symposium proceedings. Ann Intern Med. 1996;124:485-89. 
View Article PubMed Google Scholar

3. Bekelman JE, Li Y, Gross CP. Scope and impact of financial conflicts of interest in biomedical research. JAMA. 2003;289:454-65.

PubMed Google Scholar

4. Moses H, Martin JB. Academic relationships with industry: a new model for biomedical research. JAMA. 2001;285:933-35.

View Article PubMed Google Scholar

5. Pritchard MS. Conflicts of interest: conceptual and normative issues. Acad Med.1996;71:1305-13. View Article PubMed Google Scholar

6. Boyd EA, Bero LA. Assessing faculty financial relationships with industry: a case study. JAMA. 2000;284:2209-14.

View Article PubMed Google Scholar

7. Objectivity in Research, 60 Federal Register 35810 (1995) (codified at 45 CFR, 94).

8. Frankel M. Perception, reality, and the political context of conflict of interest in university-industry relationships. Acad Med. 1996;71:1297-1304.

View Article $\underline{\text { PubMed }}$ Google Scholar

9. Council on Scientific Affairs and Council on Ethical and Judicial Affairs, American Medical Association. Conflicts of interest in medical center/industry research relationships. JAMA. 1990;263:2790.

PubMed

The viewpoints expressed on this site are those of the authors and do not necessarily reflect the views and policies of the AMA.

(C) 2003 American Medical Association. All Rights Reserved. 